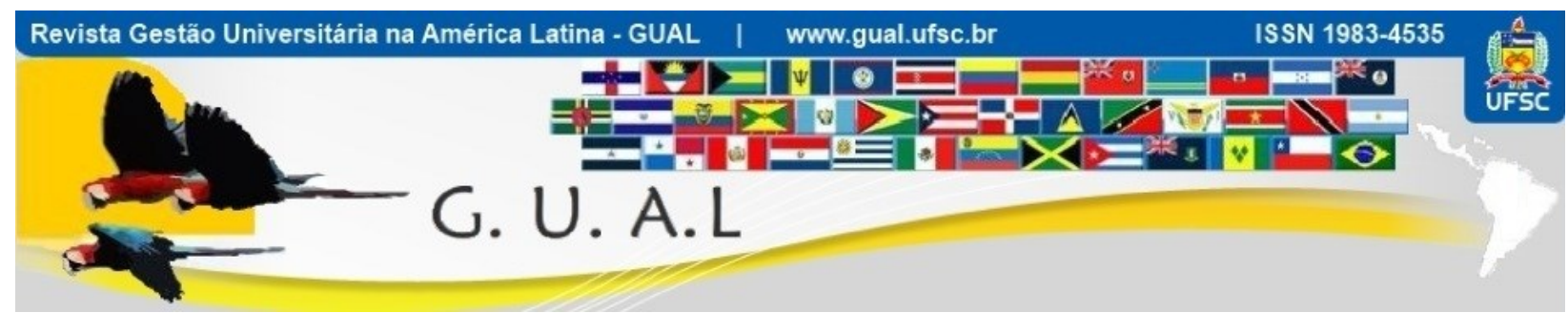

DOI: http://dx.doi.org/10.5007/1983-4535.2017v10n3p296

\title{
ANÁLISE DOS EGRESSOS DE DOUTORADO QUANTO AOS REQUISITOS PARA SEREM DOCENTES DA PÓS- GRADUAÇÃO STRICTO SENSU
}

\section{ANALYSIS OF PHD GRADUATES REGARDING THE REQUIREMENTS TO BE STRICTO SENSU GRADUATE TEACHERS}

Maurício Rissi, Doutor

Universidade Federal de Santa Catarina - UFSC

mauricio.rissi@ufsc.br

Anderson Sasaki Vasques Pacheco, Doutor Centro Universitário de Brusque - UNIFEBE sasaki.anderson@gmail.com

Karin Vieira da Silva, Doutora Centro Universitário de Brusque - UNIFEBE vieira.karin@gmail.com

Jefte Silvestre Filho Universidade Federal de Santa Catarina - UFSC jeftefilhoufsc@,gmail.com

Rafael Feijó Vieira Vecchietti, Graduando Universidade Federal de Santa Catarina - UFSC rafaelvecchietti@gmail.com

Recebido em 19/maio/2016

Aprovado em 21/julho/2017

Sistema de Avaliação: Double Blind Review 


\title{
RESUMO
}

Os programas de pós-graduação stricto sensu em nível de doutorado têm formado doutores para atuar na sociedade, em especial, no ensino, na pesquisa e na extensão universitária. Sendo o título de doutor o último da carreira acadêmica, questiona-se se o novo doutor está habilitado para formar novos mestres e doutores. Nesse contexto, o objetivo geral desta pesquisa é analisar os currículos dos egressos dos programas em questão frente aos requisitos sugeridos pela Capes para que se atue como professor em programas de pós-graduação stricto sensu. Para tanto, o método delineado foi um estudo descritivo, e classifica-se como pesquisa de campo, com abordagem quantitativa, com análise estatística, por meio de medidas descritivas. Foram escolhidos para essa pesquisa os programas de pós-graduação em Administração da UFMG, UFRGS e UFSC, que possuem diferentes conceitos atribuídos pela Capes, respectivamente 6, 5 e 4. Como principais resultados, destaca-se o baixo atendimento aos requisitos por parte dos egressos, com menos de $20 \%$ dos egressos atendendo simultaneamente os critérios de produção bibliográfica e orientações concluídas. Porém, destaca-se que em torno de $70 \%$ dos egressos estão empregados em universidades ou institutos públicos e universidades privadas.

Palavras chave: Gestão Universitária; Egressos da Pós-Graduação Stricto Sensu; Requisitos Capes para mestrados.

\begin{abstract}
The stricto sensu graduate degree programs at doctoral level have trained $\mathrm{PhDs}$ to work for society, especially in teaching, research and extension programs. As the $\mathrm{PhD}$ title is the last of the academic career, it is questioned if the new doctor is qualified to train other masters and $\mathrm{PhD}$. In this context, the objective of this research is to analyze PhDs curriculums comparing with the requirements suggested by Capes to act as teacher in stricto sensu graduate programs. Thus, the method outlined was a descriptive study, and it was classified as field research, quantitative approach, statistical analysis, through descriptive measures. For this research, it was delineated the business graduate programs from UFMG, UFRGS and UFSC. The main results reveals the low meet of the requirements by the graduates, with less than $20 \%$ of the $\mathrm{PhDs}$ attending simultaneously the bibliographic production and completed advisors criteria. However, it is noteworthy that around $70 \%$ of graduates are employed in public and private universities and institutes.
\end{abstract}

Keywords: University Management; Former Students Graduate Stricto Sensu; Requirements Capes for masters. 


\section{INTRODUÇÃO}

O sistema de pós-graduação brasileiro vem progressivamente ganhando reconhecimento internacional e alcança significativos número de evolução, fomentados por esforços acadêmicos e políticos (FRANÇA, 2012).

No país, a formação de mestres e doutores é realizada pelos programas de pósgraduação stricto sensu em instituições públicas e privadas. Cada programa é autorizado a funcionar pelo Conselho Nacional de Educação, após avaliação positiva efetuada pela Coordenação de Aperfeiçoamento de Pessoal de Nível Superior (Capes), fundação do Ministério da Educação (MEC).

Para além disso, a Capes cumpre também funções estruturantes no que tange a consolidação e expansão do pós-graduação stricto sensu, "sendo responsável por sua avaliação, pelo acesso e divulgação da produção científica brasileira; pelos investimentos na formação de recursos de alto nível no país e exterior; pela promoção da cooperação científica internacional, entre outros" (FRANÇA, 2012, p.45).

No escopo da Gestão Universitária, os programas de pós-graduação devem orientar suas ações para a adequada formação de seu corpo discente, que além das diretrizes curriculares, do senso crítico necessário para formação enquanto cidadãos, também devem se preocupar com o mercado de trabalho de seus egressos. Afinal, esses egressos possivelmente atuarão como futuros pares dos docentes que já atuam na pós-graduação stricto sensu.

Em pesquisa realizada por Ortigoza, Poltroniéri e Machado (2012), foram apresentados relevantes indicativos sobre a forte atuação de egressos de cursos de pósgraduação como agentes formadores em distintas regiões do Brasil e do exterior, e ressaltouse que a atuação profissional dos egressos destes cursos deve, portanto, ser uma dimensão importante no processo de avaliação institucional.

Tendo em conta a atuação da Capes na regulação e qualificação da pós-graduação brasileira e o papel dos programas de pós-graduação na formação de recursos humano qualificados para atuação na área de ciência e tecnologia surge a seguinte pergunta de pesquisa: os egressos dos cursos de doutorados cumprem os requisitos sugeridos pela Capes para atuarem como professores de programas de pós-graduação stricto sensu?

Por conveniência, optou-se por analisar os egressos do curso de doutorado do programa de pós-graduação em Administração da Universidade Federal de Santa Catarina, que tem conceito quatro e compará-lo com egressos de outros programas com diferentes 
conceitos, desde que universidades públicas federais. Assim, como objetos de estudo foram escolhidos os programas em Administração das Universidades Federais de Minas Gerais (UFMG), Rio Grande do Sul (UFRGS), e de Santa Catarina (UFSC).

Para responder à pergunta de pesquisa, foram delineados os seguintes objetivos.

\subsection{OBJETIVOS GERAL E ESPECÍFICOS}

O objetivo geral desta pesquisa é analisar os currículos dos egressos dos programas em questão frente aos requisitos sugeridos pela Capes para que se atue como professor em programas de pós-graduação stricto sensu.

Para atingir o objetivo geral foram delineados os seguintes objetivos específicos:

a) Descrever os requisitos sugeridos no documento de área para atuação como docente na pós-graduação stricto sensu;

b) Verificar a pontuação obtida com a publicação em periódicos científicos no quadriênio 2013-2016;

c) Identificar as orientações de trabalhos de iniciação científica, mestrado e doutorado desses egressos;

d) Descrever o perfil profissional dos egressos dos programas.

\section{FUNDAMENTAÇÃO TEÓRICA}

Neste capítulo abordam-se sucintamente os três constructos essenciais para a realização desta pesquisa, sendo eles: a gestão universitária, que segundo a perspectiva desta pesquisa significa incluir nas diretrizes dos programas universitários elementos necessários a consecução dos objetivos; um breve panorama da pós-graduação stricto sensu no Brasil; e por fim, os requisitos necessários para se atuar como docente nesses programas de pós-graduação.

\subsection{GESTÃO UNIVERSITÁRIA}

A Gestão Universitária pode ser entendida como um subcampo científico da Administração. Como sinônimos são costumeiramente vistos: Administração Universitária; Administração/Gestão de Instituições de Ensino/Educação Superior.

No entendimento dos autores desta pesquisa, é uma premissa dos pesquisadores desse subcampo científico, que as instituições de ensino superior, são complexas e distintas de quaisquer outras organizações, necessitando de especificidades e diferentes ferramentas e 
técnicas gerenciais. De acordo com Santos e Bronnemann (2013), a complexidade que diferencia as instituições de ensino superior de outros tipos de organizações está essencialmente relacionada com a sua peculiar estrutura, organização e com objetivos que almejam.

As Universidades são organizações sui generis, sendo o único tipo de organização diferenciada pela Constituição Federal de 1988, o que lhe outorga prerrogativas de autonomia de sua gestão. Elas ainda são consideradas por muitos autores da área da gestão universitária, como sendo organizações complexas. (MELO, 2002, MEYER JR., 2004, NOGUEIRA; GARCIA; RAMOS, 2012, ANDRIGUETTO JUNIOR et al., 2012).

As instituições de educação superior, de acordo com sua organização e respectivas prerrogativas acadêmicas, podem ser credenciadas como faculdades; centros universitários; e universidades. As Universidades se diferenciam pela indissociabilidade entre ensino, pesquisa e extensão.

De acordo com Burigo, Jacobsen e Wiggers (2016, p.73), “a gestão universitária é complexa e diferenciada, não havendo regra ou princípio que possa ser indiscriminadamente aplicado a todas as universidades ou IES". Isto porque, segundo as autoras, "em especial as universidades, contêm especificidades de ensino, pesquisa e extensão, de orçamento e finanças, de gerenciamento de seus recursos e de desenvolvimento da sua área de gestão de pessoas".

Schlickmann (2013, p.47) conceitua Administração Universitária como sendo o:

(...) processo de planejar, organizar, liderar e controlar o trabalho dos membros da universidade, e de usar todos os seus recursos disponíveis para atingir os objetivos de: formar quadros profissionais de nível superior; realizar pesquisa e extensão; bem como dominar e cultivar o saber humano.

$\mathrm{Na}$ interpretação dos autores desta pesquisa, Schlickmann (2013) foi assertivo ao conceituar Administração Universitária fazendo uma adaptação do conceito de Administração de Stoner e Freeman (2000, apud SCHLICKMANN, 2013), com o conceito de universidade da Lei de Diretrizes de Bases da Educação de 1996.

Nesse sentido, a Gestão Universitária pode ser entendida como conhecimentos, ferramentas e técnicas da ciência da administração adaptados e aplicados à consecução dos objetivos desse tipo tão peculiar de organização. 


\subsection{PÓS-GRADUAÇÃO STRICTO SENSU}

A formação de novos pesquisadores no Brasil é de competência dos programas de pósgraduação stricto sensu, que tem como um de seus propósitos a qualificação de corpo docente para instituições de ensino superior e pesquisadores aptos a contribuir para o sistema educacional e para a ciência como um todo. (COMUNELO et al., 2012).

A pós-graduação stricto sensu no Brasil, que compreende cursos de mestrado e doutorado, é oferecida por instituições de ensino superior, que podem ser públicas ou privadas. Atualmente totalizam 3.525 cursos de mestrados, 2.380 cursos de doutorados, e 977 cursos de mestrados profissionais em todas as áreas de avaliação. Só na área de avaliação da “Administração, Contábeis e Turismo" são respectivamente 108, 65, e 107. (SUCUPIRA, 2016).

Maccari, Riccio e Martins (2013) destacam que avaliar o sistema educacional é uma questão central para o desenvolvimento nacional e que a pós-graduação atua como um instrumento eficaz para a qualificação de recursos humanos capazes de contribuir substancialmente para a competitividade nacional no âmbito da ciência e da tecnologia.

No Brasil, a pós-graduação stricto sensu é avaliada desde 1976, pela Coordenação de Aperfeiçoamento de Pessoal de Nível Superior (Capes), fundação do Ministério da Educação (MEC). Vale destacar que, segundo Igarashi (2008, p.122) dentro os objetivos da Capes ao avaliar os programas de pós-graduação estão:

(...) impulsionar o sistema de pós-graduação no contexto nacional; oferecer a cada programa um parecer criterioso a respeito de seu desempenho, de forma a auxiliar na promoção de seu aprimoramento; montar um banco de dados sobre a situação da pós-graduação no Brasil; estabelecer um padrão de qualidade para os programas de pós-graduação no Brasil; oferecer subsídios para informar os pareceres sobre criação e renovação dos cursos de mestrado e doutorado brasileiro; oferecer subsídios para a definição de políticas de desenvolvimento da pós-graduação.

Martins et al. (2012, p.157) salientam que a atenção da Capes no cumprimento de seu papel levou-a a uma busca permanente pelo melhoramento dos seus sistemas de avaliação, com o objetivo de permanecer "servindo de instrumento impulsionador da pós-graduação brasileira na busca de um padrão de excelência científica para os mestrados e doutorados no país".

Segundo Maccari et al. (2014), o sistema nacional da Capes que avalia os programas de pós-graduação stricto sensu vem sendo desenvolvido e sofre melhoria contínuas desde 
1976. Entretanto, foi a partir de 1998 que os resultados das melhorais no sistema avaliativo ficaram mais visíveis, pois marcou a implementação de um "sistema padronizado com parâmetros de qualidade (notas, quesitos de qualidade da produção científica e de formação de alunos) considerados fatores primordiais para a melhoria do desempenho dos programas, em substituição aos conceitos adotados até então". (MARTINS, et al., 2012, p.157).

Maccari et al. (2014, p.371) corroboram e complementam esse fato ao ressaltarem que "um marco importante em sua evolução ocorreu no final da década de 1990, quando houve sua informatização e a adoção de critérios mais rígidos para atribuição de notas aos programas". Os autores afirmam também que "desde então, o sistema vem mantendo-se estável, com avanços incrementais em seus quesitos e itens de avaliação".

Atualmente a Capes avalia os programas em uma periodicidade de quatro anos, atribuindo um conceito de 1 (um) a 7 (sete) para cada programa. Os programas que recebem conceitos um ou dois, tem canceladas as autorizações de funcionamento e o reconhecimento dos cursos de mestrado e/ou doutorado. O conceito três significa desempenho regular, considerado padrão mínimo de qualidade. Programas com conceito quatro são considerados de bom desempenho e o conceito cinco é a nota máxima para programas só com cursos de mestrado. Os conceitos seis e sete indicam desempenho ao alto padrão internacional. (CAPES, 2016).

\subsection{REQUISITOS PARA ATUAR NA PÓS-GRADUAÇÃO STRICTO SENSU}

Nas últimas décadas, segundo Maccari et al. (2014), o monitoramento e avaliação do desempenho das instituições de ensino superior, suportadas por instrumentos próprios de avaliação, tornaram-se relevantes dispositivos para a promoção de melhorias e desenvolver os sistemas educacionais de diversos países. Para os autores, “isso é fato principalmente, para as nações que apostam no domínio tecnológico como meio para promover o progresso e o bemestar social”. (MACCARI et al., 2014, p.370).

No Brasil, as universidades como gozam da autonomia didático-científica, administrativa e de gestão financeira e patrimonial conforme lhe confere o artigo 207 da Constituição Federal, portanto, livre para estabelecer suas próprias diretrizes de formação. Contudo os egressos atuarão na sociedade, e a priori, a pós-graduação stricto sensu em nível de doutorado forma futuros profissionais para "ensino, pesquisa e extensão", que virão a atuar também na pós-graduação stricto sensu. 
De acordo com Ortigoza, Poltroniéri e Machado (2012) a Capes tem expressado claramente a importância da atuação dos alunos formados em programas de pós-graduação nacionais como um instrumento essencial a ser considerado no processo de avaliação dos programas.

Portanto, é razoável de se esperar que os cursos de doutorados estejam atentos aos requisitos para se atuar na pós-graduação stricto sensu, e incluam em suas diretrizes de formação elementos que possam fazer que seus doutorandos atendam a esses requisitos.

Os requisitos supracitados, necessários para que se atue em programas de pósgraduação stricto sensu são estabelecidos por cada área de avaliação da Capes. Esses requisitos estão estabelecidos no "Documento de Área" e também no documento "Orientações para novos APCNs" considerando a área de "Administração, Contábeis e Turismo".

O Documento de Área baliza o processo de avaliação que a Capes conduz nos programas de pós-graduações brasileiros, que, por conseguinte, deveria balizar os gestores de cada programa interessados em obter um bom conceito nesse processo avaliativo.

A Capes estabelece cinco quesitos de avaliação, sendo eles: (1) Proposta do Programa, (2) Corpo Docente, (3) Corpo Discente, (4) Produção Intelectual, e (5) Inserção Social. A cada área compete estabelecer dentro de cada quesito, os itens do quesito e os respectivos pesos dentro do cômputo do conceito atribuído ao programa.

Maccari, Lima e Riccio (2010), ao buscarem compreender o funcionamento do sistema de avaliação utilizado pela Capes e a utilização do mesmo em programas de pósgraduação, concluíram que os critérios de avaliação e os itens que os compõem são bem definidos e amplamente conhecidos pela comunidade acadêmica e que, desta forma, o sistema de avaliação acaba por ter grande influência na configuração e desenvolvimento de programas de pós-graduação. Assim sendo:

(...) os níveis de qualidade exigidos pelos parâmetros do sistema ajudam a melhorar o desempenho individual de um programa, ou seja, quando a CAPES estabelece as diretrizes da avaliação, dimensiona as metas e especifica as métricas de sistema de avaliação, tudo isso permite aos programas identificar as exigências de qualidade a serem alcançadas, bem como a participação de cada um no desenvolvimento local, regional e nacional. (MACCARI; LIMA; RICCIO, 2010, p.92).

Os autores também destacam alguns aspectos que são amplamente afetados pelo sistema de avaliação no âmbito de programas de pós-graduação, nomeadamente: a) direcionador estratégico dos programas, no sentido de influenciar os seus planos de ações e metas; b) 
qualidade, tendo em perspectiva os requisitos de qualidade mínima exigidos e o direcionamento de esforços e recursos para a melhoria contínua; c) produtividade, pois a natureza predominantemente quantitativa do sistema avaliativo da Capes leva ao aumento da produtividade e equilibra a atuação dos atores que constituem os programas, e, d) inserção social, uma vez que o sistema de avaliação induz os programas a aumentarem a sua inserção e impacto social.

Dentre os itens dos quesitos estabelecidos pela área de "Administração, Contábeis e Turismo", alguns estão diretamente associados ao corpo docente e, portanto, de fundamental importância para que os gestores dos programas incluam nas diretrizes de formação de seus doutorandos, e devam ser encarados como um dos objetivos da formação do futuro doutor. Sendo eles: (a) orientações concluídas de iniciação científica e mestrado, (b) Produção Intelectual qualificada e (c) coordenação de projetos de pesquisa.

(a) Pelo menos 50\% do núcleo docente permanente deve possuir experiência anterior em orientação de mestrado, doutorado ou iniciação científica.

(b) Para as propostas de mestrados, pelo menos 50\% dos docentes deve ter alcançado pelo menos 150 pontos nos três anos, sendo que a média esperada por docente é definida entre 60 e 105 pontos nos três anos.

Por fim, vale ressaltar que, conforme Comunelo et al. (2012), a competência profissional do corpo docente necessita de relevantes investimentos em pesquisas que abranjam a sua formação, especialmente, em um momento em que o papel do professor tradicional passa por profundas transformações em seu cerne, e a construção de significativo conhecimento requer novas competências docentes.

\section{3 'PROCEDIMENTOS METODOLÓGICOS}

De acordo com Santos (2012, p.197) "na pesquisa descritiva é feita a descrição das características de uma determinada população, estudo descritivo de determinado fenômeno com suas variáveis". O presente estudo pode ser denominado como descritivo já que pretende comparar o cumprimento de requisitos por parte de egressos de doutorados de três programas de pós-graduação em Administração.

Classifica-se ainda como pesquisa de campo, com abordagem quantitativa, com análise estatística, por meio de medidas descritivas. De acordo com Severino (2007), a pesquisa de Campo pode ser entendida quando o objeto/fonte é abordado em seu meio 
ambiente próprio, e a coleta de dados feita sem intervenção e manuseio por parte do pesquisador.

Os autores deste estudo, por conveniência, escolheram analisar os egressos do curso de doutorado do programa de pós-graduação em Administração da Universidade Federal de Santa Catarina, que tem conceito quatro e compará-lo com egressos de outros programas com diferentes conceitos. Foi escolhido o programa de pós-graduação em Administração da Universidade Federal do Rio Grande do Sul, que tem conceito cinco. O programa de pósgraduação em Administração da Universidade Federal de Minas Gerais foi escolhido por ser a única universidade federal com conceito seis, nessa área de avaliação.

Foram coletados dados públicos das plataformas Sucupira e Lattes durante a segunda quinzena de julho e primeira quinzena de agosto do ano de 2016. Primeiro, buscou-se na plataforma Sucupira os nomes dos egressos, por ano e programa analisado, que concluíram nos anos de 2013, 2014 e 2015.

Depois, na plataforma Lattes, buscou-se três tipos de informação para cada egresso: (1) publicações em periódicos; (2) orientações concluídas; e (3) atuação profissional.

Para as publicações em periódicos, foram coletados por egresso: título do artigo, periódico, ano de publicação dos anos 2013, 2014, 2015 e 2016. Com essas informações, buscou-se na plataforma Sucupira o extrato qualis do periódico na área de "Administração, Contábeis e Turismo" e o maior extrato qualis daquele periódico em qualquer área de avaliação.

Para as orientações concluídas, buscou-se apenas o quantitativo das orientações concluídas de iniciação científica, mestrado e doutorado por egresso.

Para a atuação profissional foi coletado, por egresso, todos os vínculos que constavam como atual. A partir da análise da informação coletada, os vínculos foram classificados em oito categorias a conhecer: (1) Bolsista Pós-Doutorado ou pesquisador de grupo; (2) Ocupação Não Acadêmica; (3) Professor - Faculdade ou Centro Universitário; (4) Professor Instituto Federal; (5) Professor - Universidade Estadual; (6) Professor - Universidade Federal; (7) Professor - Universidade Privada; (8) Sem Ocupação.

A experiência com coordenação de projetos de pesquisa, apesar de ser requisito para atuar em programas stricto sensu, foi deixada de fora do escopo de presente trabalho, por entender que mesmo que o programa possa preparar o doutorando para coordenação de projetos, dificilmente ele seria o coordenador enquanto doutorando. 


\section{APRESENTAÇÃO DOS RESULTADOS}

Um breve comentário dos programas analisados faz-se necessário para uma melhor compreensão dos resultados obtidos.

O Programa de Pós-Graduação em Administração da Universidade Federal de Minas Gerais, avaliado com conceito 6, na avaliação referente aos anos de 2010-2013, nasceu em 1973 com o curso de mestrado. Seu curso de doutorado foi implantado em 1995 e até o final de 2015, esse programa titulou 619 mestres e 176 doutores. (SUCUPIRA, 2016)

Atualmente o programa conta com quatro linhas de pesquisa: Mercadologia e Administração Estratégica e Operações; Gestão de Pessoas e Comportamento Organizacional; Finanças; e Estudos Organizacionais e Sociedade.

O Programa de Pós-Graduação em Administração da Universidade Federal de Santa Catarina, avaliado com conceito 4, na avaliação referente aos anos de 2010-2013, nasceu em 1978 com o curso de mestrado. Seu curso de doutorado foi implantado apenas em 2008. Até o final de 2015, esse programa titulou 939 mestres e 33 doutores. (SUCUPIRA, 2016)

Atualmente o programa conta com cinco linhas de pesquisa: Finanças e Desenvolvimento Econômico; Produção e Desenvolvimento; Organizações e Sociedade; Marketing e Estratégia nas Organizações; e Gestão Universitária.

O Programa de Pós-Graduação em Administração da Universidade Federal do Rio Grande do Sul, avaliado com conceito 5, na avaliação referente aos anos de 2010-2013, nasceu em 1972 com o curso de mestrado em Administração Pública e Administração de Empresas. Seu curso de doutorado foi implantado em 1994 e até o final de 2015, esse programa titulou 1452 mestres e 245 doutores. (SUCUPIRA, 2016)

Atualmente o programa conta com seis linhas de pesquisa: Marketing; Finanças; Estudos Organizacionais; Gestão de Sistemas e Tecnologia da Informação; Gestão de Pessoas; e Inovação, Tecnologia e Sustentabilidade.

A partir dos dados coletados, foram feitas algumas análises estatísticas que serão comentadas ao longo deste capítulo.

Na Tabela 01 pode ser observado o quantitativo de egressos por ano e o programa das instituições analisadas. O programa de Administração da UFSC, que tem conceito quatro, tem menos da metade dos egressos em relação às outras instituições no mesmo período, e também não apresenta grande variação de egressos por ano. A UFMG foi a que formou mais doutores em Administração no período analisado, com 67 egressos, contra 65 da UFRGS. 
Tabela 01 Egressos por ano.

\begin{tabular}{c|c|c|c|c}
\hline Ano & UFMG & UFRGS & UFSC & $\begin{array}{c}\text { Total } \\
\text { por ano }\end{array}$ \\
\hline $\mathbf{2 0 1 3}$ & 17 & 29 & 9 & $\mathbf{5 5}$ \\
\hline $\mathbf{2 0 1 4}$ & 28 & 17 & 9 & $\mathbf{5 4}$ \\
\hline $\mathbf{2 0 1 5}$ & 22 & 19 & 11 & $\mathbf{5 2}$ \\
\hline $\begin{array}{c}\text { Total por } \\
\text { instituição }\end{array}$ & $\mathbf{6 7}$ & $\mathbf{6 5}$ & $\mathbf{2 9}$ & \\
\hline
\end{tabular}

Fonte: Elaborado pelos autores a partir da Plataforma Lattes e Plataforma Sucupira.

Para se propor novo curso de mestrado, pelo menos metade do corpo docente precisa apresentar experiência de orientação em mestrado, doutorado ou iniciação científica, de acordo com as orientações para novos APCNs publicado em 2012 e atualmente vigente. Com isso, observa-se na Tabela 02, que nos três programas das instituições analisadas, o número de egressos sem experiência de orientação passa de $50 \%$ e em duas delas estão na casa dos $70 \%$. Não foi levada em consideração a experiência em orientação em graduação ou pós-graduação lato sensu, já que estas não são requisitos para se atuar na pós-graduação stricto sensu.

Tabela 02 Egressos com orientações concluídas de iniciação científica ou mestrado ou doutorado.

\begin{tabular}{c|c|c|c|c|c|c}
\hline \multirow{2}{*}{$\begin{array}{c}\text { Possui orientação concluída } \\
\text { de iniciação científica, ou } \\
\text { mestrado ou doutorado? }\end{array}$} & \multicolumn{2}{|c|}{ UFMG } & \multicolumn{2}{c|}{ UFRGS } & \multicolumn{2}{c}{ UFSC } \\
\cline { 2 - 7 } & $\begin{array}{c}\text { Freq. } \\
\text { Absoluta }\end{array}$ & $\begin{array}{c}\text { Freq. } \\
\text { Relativa }\end{array}$ & $\begin{array}{c}\text { Freq. } \\
\text { Absoluta }\end{array}$ & $\begin{array}{c}\text { Freq. } \\
\text { Relativa }\end{array}$ & $\begin{array}{c}\text { Freq. } \\
\text { Absoluta }\end{array}$ & $\begin{array}{c}\text { Freq. } \\
\text { Relativa }\end{array}$ \\
\hline Sim & 30 & $44,78 \%$ & 7 & $24,14 \%$ & 20 & $30,77 \%$ \\
\hline Não & 37 & $55,22 \%$ & 22 & $75,86 \%$ & 45 & $69,23 \%$ \\
\hline Total & $\mathbf{6 7}$ & $\mathbf{1 0 0 , 0 0 \%}$ & $\mathbf{2 9}$ & $\mathbf{1 0 0 , 0 0 \%}$ & $\mathbf{6 5}$ & $100,00 \%$ \\
\hline
\end{tabular}

Fonte: Elaborado pelos autores a partir da Plataforma Lattes e Plataforma Sucupira.

Para quem está envolvido no mundo da pós-graduação sabe que a maior pressão é sobre a produção em periódico científico com bom extrato Qualis na área de avaliação do programa.

Os professores sofrem essa pressão por parte dos pares e da Capes, e os discentes por parte de seus orientadores. Apesar da produção intelectual em periódico Qualis representar não mais que $35 \%$ do peso total dos itens avaliados no programa, é o item que tem maior peso, e o que figura entre as principais preocupações dos docentes da pós-graduação.

$\mathrm{Na}$ Tabela 03, identificou-se o percentual de egressos que conseguiram obter 50 pontos ou mais na média anual, considerando os anos de 2013 a 2016. 
O programa com maior frequência relativa de egressos com produção com cinquenta pontos ou mais foi a UFRGS com 36,92\%, seguido da UFSC, com 31,03\% e por último ficou a UFMG com apenas $22,39 \%$ de egressos com essa pontuação.

Tabela 03 Egressos com 50 pontos ou mais na média anual.

\begin{tabular}{c|c|c|c|c|c|c}
\hline $\begin{array}{c}\text { Tem 50 pontos ou } \\
\text { mais na média } \\
2013-2016\end{array}$ & \multicolumn{2}{|c|}{ UFMG } & \multicolumn{2}{c}{ UFRGS } & \multicolumn{2}{c}{ UFSC } \\
\hline & $\begin{array}{c}\text { Freq. } \\
\text { Absoluta }\end{array}$ & $\begin{array}{c}\text { Freq. } \\
\text { Relativa }\end{array}$ & $\begin{array}{c}\text { Freq. } \\
\text { Absoluta }\end{array}$ & $\begin{array}{c}\text { Freq. } \\
\text { Relativa }\end{array}$ & $\begin{array}{c}\text { Freq. } \\
\text { Absoluta }\end{array}$ & $\begin{array}{c}\text { Freq. } \\
\text { Relativa }\end{array}$ \\
\hline Sim & 15 & $22,39 \%$ & 24 & $36,92 \%$ & 9 & $31,03 \%$ \\
\hline Não & 52 & $77,61 \%$ & 41 & $63,08 \%$ & 20 & $68,97 \%$ \\
\hline Total: & $\mathbf{6 7}$ & $\mathbf{1 0 0 , 0 0 \%}$ & $\mathbf{6 5}$ & $\mathbf{1 0 0 , 0 0 \%}$ & $\mathbf{2 9}$ & $\mathbf{1 0 0 , 0 0 \%}$ \\
\hline
\end{tabular}

Fonte: Elaborado pelos autores a partir da Plataforma Lattes e Plataforma Sucupira.

Sem nenhuma produção foram encontrados 26 egressos, sendo 5 da UFMG, 11 da UFRGS e 10 da UFSC. Chamou a atenção dos pesquisadores o elevado número de egressos da UFSC sem nenhuma produção, representando $34,48 \%$ do total, contra $16,92 \%$ da UFRGS e $7,46 \%$ da UFMG.

Observando a frequência acumulada apresentada na Tabela 04, tem-se 70,15\%, $50,77 \%$ e $62,07 \%$ com menos de quarenta pontos de média, valores respectivos a UFMG, UFRGS e UFSC.

Tabela 04 Faixa de pontuação média por egresso e programa.

\begin{tabular}{|c|c|c|c|c|c|c|c|c|c|}
\hline & \multicolumn{3}{|c|}{ UFMG } & \multicolumn{3}{|c|}{ UFGRS } & \multicolumn{3}{|c|}{ UFSC } \\
\hline & $\begin{array}{l}\text { Freq. } \\
\text { Abs. }\end{array}$ & $\begin{array}{l}\text { Freq. } \\
\text { Rel. }\end{array}$ & $\begin{array}{l}\text { Freq. } \\
\text { Acum. }\end{array}$ & $\begin{array}{l}\text { Freq. } \\
\text { Abs. }\end{array}$ & $\begin{array}{l}\text { Freq. } \\
\text { Rel. }\end{array}$ & $\begin{array}{l}\text { Freq. } \\
\text { Acum. }\end{array}$ & $\begin{array}{l}\text { Freq. } \\
\text { Abs. }\end{array}$ & $\begin{array}{c}\text { Freq. } \\
\text { Rel. }\end{array}$ & $\begin{array}{l}\text { Freq. } \\
\text { Acum. }\end{array}$ \\
\hline $\begin{array}{r}\text { Sem } \\
\text { pontos }\end{array}$ & 5 & $7,46 \%$ & $7,46 \%$ & 11 & $16,92 \%$ & $16,92 \%$ & 10 & $34,48 \%$ & $34,48 \%$ \\
\hline$>0$ e $<20$ & 19 & $28,36 \%$ & $35,82 \%$ & 7 & $10,77 \%$ & $27,69 \%$ & 2 & $6,90 \%$ & $41,38 \%$ \\
\hline $\begin{array}{r}>=20 \text { e }< \\
40\end{array}$ & 23 & $34,33 \%$ & $70,15 \%$ & 15 & $23,08 \%$ & $50,77 \%$ & 6 & $20,69 \%$ & $62,07 \%$ \\
\hline $\begin{array}{r}>=40 \mathrm{e}< \\
60\end{array}$ & 9 & $13,43 \%$ & $83,58 \%$ & 11 & $16,92 \%$ & $67,69 \%$ & 3 & $10,34 \%$ & $72,41 \%$ \\
\hline$>=60$ & 11 & $16,42 \%$ & $100,00 \%$ & 21 & $32,31 \%$ & $100,00 \%$ & 8 & $27,59 \%$ & $100,00 \%$ \\
\hline Total & 67 & $100,00 \%$ & & 65 & $100,00 \%$ & & 29 & $100,00 \%$ & \\
\hline
\end{tabular}

Fonte: Elaborado pelos autores a partir da Plataforma Lattes e Plataforma Sucupira. 
Os dados apresentados nas tabelas 03 e 04 referem-se ao extrato qualis de cada publicação, extraído da plataforma Sucupira considerando o Qualis da área de avaliação de "Administração, Contábeis e Turismo" e considerando a pontuação apresentada no relatório da mesma área, apresentado na tabela 05 a seguir.

Tabela 05 Pontuação de cada extrato Qualis

\begin{tabular}{c|c}
\hline Extrato & Pontos \\
\hline A1 & 100 \\
\hline A2 & 80 \\
\hline B1 & 60 \\
\hline B2 & 50 \\
\hline B3 & 30 \\
\hline B4 & 20 \\
\hline B5 & 10 \\
\hline C & 0 \\
\hline Sem Qualis & 0 \\
\hline
\end{tabular}

Fonte: Adaptado do Relatório de Área de “Administração, Contábeis e Turismo" 2013.

Na Tabela 06 são apresentadas as frequências absolutas e relativas das publicações por programa e também por extrato Qualis. Foi adicionado também nessa tabela, o quantitativo das publicações sem Qualis na área de avaliação "Administração, Contábeis e Turismo" e os artigos com Qualis maior em outra área de avaliação. Foram identificados também 3 (4,55\%), $7(10,77 \%)$ e $7(24,14 \%)$ egressos sem nenhum artigo com ou sem Qualis, respectivamente UFMG, UFRGS e UFSC.

Tabela 06 Distribuição das produções por instituição

\begin{tabular}{c|c|c|c|c|c|c}
\hline & \multicolumn{2}{|c|}{ UFMG } & \multicolumn{2}{c|}{ UFRGS } & \multicolumn{2}{c}{ UFSC } \\
\hline & $\begin{array}{c}\text { Freq. } \\
\text { Absoluta }\end{array}$ & $\begin{array}{c}\text { Freq. } \\
\text { Relativa }\end{array}$ & $\begin{array}{c}\text { Freq. } \\
\text { Absoluta }\end{array}$ & $\begin{array}{c}\text { Freq. } \\
\text { Relativa }\end{array}$ & $\begin{array}{c}\text { Freq. } \\
\text { Absoluta }\end{array}$ & $\begin{array}{c}\text { Freq. } \\
\text { Relativa }\end{array}$ \\
\hline A1 & 1 & $0,31 \%$ & 11 & $2,82 \%$ & 2 & $1,83 \%$ \\
\hline A2 & 26 & $8,10 \%$ & 37 & $9,49 \%$ & 13 & $11,93 \%$ \\
\hline B1 & 21 & $6,54 \%$ & 33 & $8,46 \%$ & 9 & $8,26 \%$ \\
\hline B2 & 41 & $12,77 \%$ & 52 & $13,33 \%$ & 19 & $17,43 \%$ \\
\hline B3 & 63 & $19,63 \%$ & 78 & $20,00 \%$ & 30 & $27,52 \%$ \\
\hline B4 & 63 & $19,63 \%$ & 62 & $15,90 \%$ & 15 & $13,76 \%$ \\
\hline B5 & 16 & $4,98 \%$ & 15 & $3,85 \%$ & 3 & $2,75 \%$ \\
\hline C & 9 & $2,80 \%$ & 1 & $0,26 \%$ & 0 & $0,00 \%$ \\
\hline
\end{tabular}




\begin{tabular}{c|c|c|c|c|c|c} 
Sem Qualis & 81 & $25,23 \%$ & 101 & $25,90 \%$ & 18 & $16,51 \%$ \\
\hline Total de Artigos & 321 & $100,00 \%$ & 390 & $100,00 \%$ & 109 & $100,00 \%$ \\
\hline $\begin{array}{c}\text { Artigos com Qualis } \\
\text { maior em outra área }\end{array}$ & 147 & $45,79 \%$ & 117 & $30,00 \%$ & 41 & $37,61 \%$ \\
\hline
\end{tabular}

Fonte: Elaborado pelos autores a partir da Plataforma Lattes e Plataforma Sucupira

Nos três programas, observou-se que há uma concentração de aproximadamente $50 \%$ das publicações nos extratos B2, B3 e B4. Somando o extrato C com os sem Qualis teve-se $28,04 \%, 26,15 \%$ e $16,51 \%$ respectivamente UFMG, UFGRS e UFSC. O que significa um esforço significativo de produção, sem a respectiva valoração e reconhecimento para efeitos de avaliação da área.

Também foi observado um grande volume de produção que possuíam um Qualis maior em outra área de avaliação do que a de "Administração, Contábeis e Turismo".

Outra análise realizada está relacionada à ocupação desses egressos, a partir da informação disponibilizada nos currículos Lattes, na sessão Atuação Profissional e vínculo, foram criados oito categorias que podem ser observadas na Tabela 07 a seguir.

Tabela 07 Ocupação dos egressos

\begin{tabular}{|c|c|c|c|c|c|c|c|c|}
\hline \multicolumn{9}{|c|}{ Ocupação } \\
\hline & \multicolumn{2}{|c|}{ UFMG } & \multicolumn{2}{|c|}{ UFRGS } & \multicolumn{2}{|c|}{ UFSC } & \multicolumn{2}{|c|}{ Total } \\
\hline & $\begin{array}{c}\text { Freq. } \\
\text { Absoluta }\end{array}$ & \begin{tabular}{|c|} 
Freq. \\
Relativa
\end{tabular} & $\begin{array}{c}\text { Freq. } \\
\text { Absoluta }\end{array}$ & $\begin{array}{c}\text { Freq. } \\
\text { Relativa }\end{array}$ & \begin{tabular}{|c|} 
Freq. \\
Absoluta
\end{tabular} & $\begin{array}{c}\text { Freq. } \\
\text { Relativa }\end{array}$ & \begin{tabular}{|c|} 
Freq. \\
Absoluta
\end{tabular} & \begin{tabular}{|c|} 
Freq. \\
Relativa
\end{tabular} \\
\hline $\begin{array}{l}\text { Bolsista Pós- } \\
\text { Doutorado ou } \\
\text { pesquisador de } \\
\text { grupo }\end{array}$ & 3 & $4,48 \%$ & 2 & $3,08 \%$ & 1 & $3,45 \%$ & 6 & $3,73 \%$ \\
\hline $\begin{array}{l}\text { Ocupação Não } \\
\text { Acadêmica }\end{array}$ & 3 & $4,48 \%$ & 1 & $1,54 \%$ & 2 & $6,90 \%$ & 6 & $3,73 \%$ \\
\hline $\begin{array}{l}\text { Professor - } \\
\text { Faculdade ou } \\
\text { Centro } \\
\text { Universitária }\end{array}$ & 12 & $17,91 \%$ & 8 & $12,31 \%$ & 3 & $10,34 \%$ & 23 & $14,29 \%$ \\
\hline $\begin{array}{l}\text { Professor - } \\
\text { Instituto } \\
\text { Federal }\end{array}$ & 5 & $7,46 \%$ & 4 & $6,15 \%$ & 3 & $10,34 \%$ & 12 & $7,45 \%$ \\
\hline $\begin{array}{l}\text { Professor - } \\
\text { Universidade } \\
\text { Estadual }\end{array}$ & 2 & $2,99 \%$ & 6 & $9,23 \%$ & 7 & $24,14 \%$ & 15 & $9,32 \%$ \\
\hline $\begin{array}{l}\text { Professor - } \\
\text { Universidade } \\
\text { Federal }\end{array}$ & 35 & $52,24 \%$ & 28 & $43,08 \%$ & 8 & $27,59 \%$ & 71 & $44,10 \%$ \\
\hline
\end{tabular}




\begin{tabular}{l|c|c|c|c|c|c|c|c}
$\begin{array}{l}\text { Professor - } \\
\text { Universidade } \\
\text { Privada }\end{array}$ & 6 & $8,96 \%$ & 11 & $16,92 \%$ & 2 & $6,90 \%$ & 19 & $11,80 \%$ \\
\hline Sem Ocupação & 1 & $1,49 \%$ & 5 & $7,69 \%$ & 3 & $10,34 \%$ & 9 & $5,59 \%$ \\
\hline Total: & 67 & $100 \%$ & 65 & $100 \%$ & 29 & $100 \%$ & 161 & $100 \%$ \\
\hline
\end{tabular}

Fonte: Elaborado pelos autores a partir da Plataforma Lattes e Plataforma Sucupira.

Mesmo com o baixo atendimento aos requisitos necessários para atuar na pósgraduação stricto sensu, foi observada uma alta taxa de egressos com empregos. Apenas 9,32\% estão sem ocupação, ou estão como bolsistas de pós-doutorado ou pesquisador de grupo de pesquisa. Aproximadamente $60 \%$ dos egressos estão em empregos públicos como professor em institutos federais, universidades federais ou universidades estaduais. Sobe para $70 \%$ se considerado empregos em universidades ou institutos públicos e universidades privadas.

\section{CONCLUSÃO}

A partir do levantamento e das análises realizadas pôde-se assegurar o cumprimento dos objetivos do presente estudo. O objetivo geral dessa pesquisa foi analisar os currículos dos egressos dos programas em questão frente aos requisitos sugeridos pela Capes para que se atue como professor em programas de pós-graduação stricto sensu.

O primeiro objetivo específico foi descrever os requisitos sugeridos no documento de área para atuação como docente na pós-graduação stricto sensu. A partir dele foi identificado que para se atuar na pós-graduação stricto sensu o docente precisa cumprir essencialmente três requisitos além da aderência ao programa, sendo eles (1) orientações concluídas de iniciação científica, mestrado e doutorado, (2) Produção Intelectual qualificada, e (3) coordenação de projetos de pesquisa.

Para o segundo objetivo específico que foi verificar a pontuação obtida com a publicação em periódicos científicos no quadriênio 2013-2016, foi constado que 70\% estão abaixo dos 50 pontos de média, portanto, insuficiente para atuação em programas de pósgraduação stricto sensu. Foi verificado também que 70,15\%, 50,77\% e 62,07\% dos egressos, respectivamente UFMG, UFRGS e UFSC estão abaixo dos 40 pontos de média. Tendo ainda aproximadamente 25\% de produção não valorada, com Qualis C ou sem Qualis na área.

O terceiro objetivo específico que foi identificar as orientações de trabalhos de iniciação científica, mestrado e doutorado desses egressos, percebeu-se que 55,22\%, 75,86\%, 
e $69,23 \%$ dos egressos, respectivamente da UFMG, UFRGS e UFSC não possuem experiência em orientação nos níveis exigidos pela Capes.

Se considerar simultaneamente os egressos que possuem 50 pontos ou mais de produção em periódicos com Qualis na área e experiência de orientações concluídas em iniciação científica ou mestrado ou doutorado, atendem esses critérios apenas 11,94\%, $15,38 \%$ e $10,34 \%$ da população estudada, valores respectivos a UFMG, UFRGS e UFSC.

O quarto e último objetivo específico foi descrever o perfil profissional dos egressos dos programas. Apesar de ter sido detectado um baixo número de egressos que atendem os critérios para atuar na pós-graduação stricto sensu. Pode-se considerar que os egressos possuem um bom perfil profissional, estando, em torno de $70 \%$ com empregos em universidades ou institutos públicos e universidades privadas e apenas 9,32\% estão sem ocupação, ou estão como bolsistas de pós-doutorado ou pesquisador de grupo de pesquisa. Não apresentando grande variação entre os programas.

Propõem-se aos programas de pós-graduação stricto sensu maior atenção aos elementos pelos quais são avaliados e que de forma sistemática incluam esses requisitos na formação de seus doutorandos. Os programas poderiam, por exemplo, (a) estimular que seus doutorandos atuassem na figura de coorientador de mestrado ou iniciação científica. (b) Os programas também podem incluir na formação de seus futuros doutores a preparação para escrever, atuar e coordenar projetos de pesquisa financiados. (c) Estimular a produção com Qualis na área, com orientação na escolha dos periódicos, já que aproximadamente $25 \%$ dos artigos publicados foram em periódicos sem Qualis na área e, por conseguinte, não contabilizados.

\section{REFERÊNCIAS}

ANDRIGUETTO JUNIOR, H.et al. Estratégias acadêmicas e suas manifestações: o discurso e a prática. R. Gestão Univ. Amer. Lat. Gual, [s.1.], v. 4, n. 3, p.126-152, 5 jun. 2012. Universidade Federal de Santa Catarina (UFSC). http://dx.doi.org/10.5007/19834535.2011v4n3p126. Disponível em: <gual.ufsc.br>. Acesso em: 7 set. 2016

BURIGO, C. C. D.; LINHARES JACOBSEN, A. DE; WIGGERS, L. Mestrado Profissional em Administração Universitária: desafios e perspectivas no processo da gestão universitária. Navus-Revista de Gestão e Tecnologia, 2016. v. 6, n. 2, p. 68-78.

CAPES. 2016. Disponível em: <http://www.capes.gov.br/>. Acesso em: 07 set. 2016. 
COMUNELO, A. L. et al. Programas de pós-graduação Stricto Sensu em contabilidade: sua contribuição na formação de professores e pesquisadores. Enfoque: Reflexão Contábil, 26 abr. 2012. v. 31, n. 1. Disponível em:

$<$ http://periodicos.uem.br/ojs/index.php/Enfoque/article/view/13375>. Acesso em: 20 abr. 2017.

FRANÇA, I. A. A gestão da pós-graduação no Brasil através de seus planos nacionais: os desafios dos gestores de cursos. Revista Gestão Universitária na América Latina - GUAL, 21 dez. 2012. v. 5, n. 4. Disponível em:

$<$ http://www.periodicos.ufsc.br/index.php/gual/article/view/27507>. Acesso em: 20 abr. 2017.

IGARASHI, D. C. C. et al. A qualidade do ensino sob o viés da avaliação de um programa de pós-graduação em contabilidade: proposta de estruturação de um modelo híbrido. Revista de Administração, 2008. v. 43, n. 2, p. 117-137.

MACCARI, E. A. et al. Proposta de um modelo de gestão de programas de pósgraduação na área de Administração a partir dos sistemas de avaliação do Brasil (CAPES) e dos Estados Unidos (AACSB). Revista de Administração, 2014. v. 49, n. 2, p. 369-383.

MACCARI, E. A.; LIMA, M. C.; RICCIO, E. L. Uso do sistema de avaliação da CAPES por programas de pós-graduação em administração no Brasil. Revista de Ciências da Administração, 30 mar. 2010. v. 11, n. 25. Disponível em:

$<$ http://www.periodicos.ufsc.br/index.php/adm/article/view/13077>. Acesso em: 20 abr. 2017.

MACCARI, E. A.; RICCIO, E. L.; MARTINS, C. B. A influência do sistema de avaliação da AACSB na gestão dos programas de pós-graduação stricto sensu em Administração nos Estados Unidos. REAd. Revista Eletrônica de Administração (Porto Alegre), dez. 2013. v. 19, n. 3 , p. $738-766$.

MARTINS, C. B. et al. A influência do sistema de avaliação nos programas de pósgraduação stricto sensu brasileiro. Revista Gestão Universitária na América Latina GUAL, 21 dez. 2012. v. 5, n. 3. Disponível em:

<http://www.periodicos.ufsc.br/index.php/gual/article/view/26893>. Acesso em: 20 abr. 2017.

MELO, P. A. de. A cooperação universidade/empresa nas universidades públicas brasileiras. 2002. 330 f. Tese (Doutorado em Engenharia de Produção) - Programa de PósGraduação em Engenharia de Produção, Universidade Federal de Santa Catarina, Florianópolis, 2002.

MEYER JR., V. Planejamento universitário - ato racional, político ou simbólico: um estudo de universidades brasileiras. In: XXVIII EnANPAD, Curitiba, 2004.

NOGUEIRA, M. G. Saraiva; GARCIA, T. E. M.; RAMOS, M. G. G. NOGUEIRA, M. G. Saraiva; GARCIA, T. E. M.; RAMOS, M. G. G. Governança corporativa, responsabilidade social corporativa: a visão de atores de uma instituição de ensino superior - IES federal. R. Gestão Univ. Amer. Lat. Gual, [s.1.], v. 5, n. 3, p.222-244, 21 dez. 2012. Universidade Federal de Santa Catarina (UFSC). http://dx.doi.org/10.5007/1983- 
4535.2012v5n3p222. Disponível em: <gual.ufsc.br>. Acesso em: 7 set. 2016.- IES federal. R. Gestão Univ. Amer. Lat. Gual, [s.1.], v. 5, n. 3, p.222-244, 21 dez. 2012. Universidade Federal de Santa Catarina (UFSC). http://dx.doi.org/10.5007/1983-4535.2012v5n3p222. Disponível em: <gual.ufsc.br>. Acesso em: 7 set. 2016.

ORTIGOZA, S. A. G.; POLTRONIÉRI, L. C.; MACHADO, L. M. C. P. A atuação profissional dos egressos como importante dimensão no processo de avaliação de programas de pós-graduação. Sociedade \& Natureza, ago. 2012. v. 24, n. 2, p. 243-254.

SANTOS, I. E. dos. Manual de Métodos e Técnicas de Pesquisa Científica. 9. ed. Niterói: Impetus, 2012. $384 \mathrm{p}$.

RESOLUÇÃO CNE/CES 10, DE 16 DE DEZEMBRO DE 2004. Disponível em http://portal.mec.gov.br/cne/arquivos/pdf/rces10 04.pdf

SANTOS, L. D.; BRONNEMANN, M. R. Desafios da gestão em instituições de ensino superior: um estudo de caso a partir da percepção de diretores de centro de uma IES pública do sul do Brasil. Revista Gestão Universitária na América Latina - GUAL, 30 jan. 2013. v. 6, n. 1. Disponível em:

$<$ http://periodicos.ufsc.br/index.php/gual/article/view/26396>. Acesso em: 15 maio 2017.

SEVERINO, A. J. Metodologia do Trabalho Científico. 23. ed. São Paulo: Cortez, 2007. $304 \mathrm{p}$.

SUCUPIRA. 2016. Disponível em: <https://sucupira.capes.gov.br/>. Acesso em: 07 set. 2016. 